
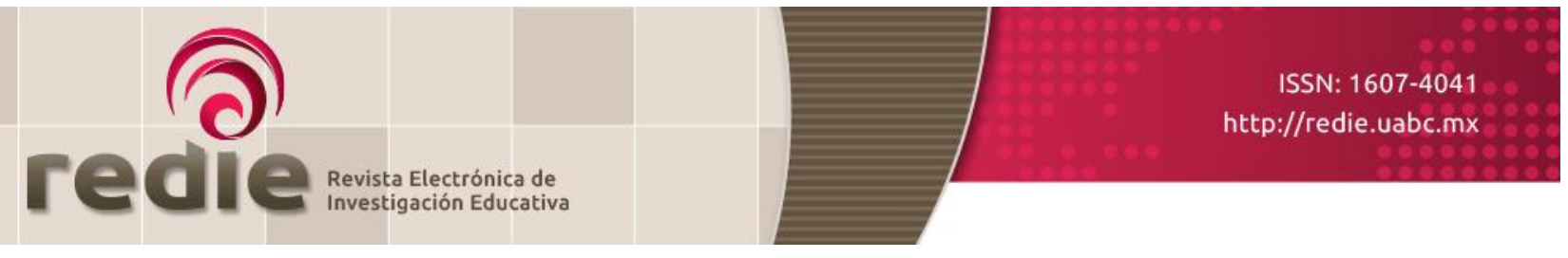

Vol. 22, 2020/e17

\title{
Adolescentes frente a los riesgos en el uso de las TIC
}

\section{Adolescents and Risks of ICT}

\author{
Jhon Richard Orosco Fabián (*) https://orcid.org/0000-0001-9035-706X \\ Rocío Pomasunco Huaytalla (*) https://orcid.org/0000-0002-8656-1479
}

(*) Universidad Nacional del Centro del Perú

(Recibido: 5 de marzo de 2018; Aceptado para su publicación: 17 de julio de 2018)

Cómo citar: Orosco, J. R. y Pomasunco, R. (2020). Adolescentes frente a los riesgos en el uso de las tıc. Revista Electrónica de Investigación Educativa, 22, e17, 1-13. https://doi.org/10.24320/redie.2020.22.e17.2298

\section{Resumen}

Las Tecnologías de la Información y la Comunicación (TIC) han impactado en adolescentes de todos los sectores de la sociedad y utilizarlas sin orientación conlleva riesgos. Este estudio evalúa la frecuencia de los riesgos en el uso de las TIC en adolescentes de la región Junín (Perú). La muestra estuvo compuesta por 955 adolescentes con edades comprendidas entre los 13 y 19 años $(M=15.21$, DT $=1.07)$ de diferentes provincias de la región Junín. La selección de participantes atendió al muestreo aleatorio estratificado. Se recogió información a través de un instrumento construido ad hoc. Los resultados muestran que existe diferencia significativa $(<.000)$ en cuanto al conocimiento de riesgos, siendo mayor en mujeres. Los principales riesgos a los que se exponen son: acceso a contenidos inapropiados (46.2\%), sexting (24.9\%), cyberbullying (20.9\%), grooming (20.8\%), sexcasting (14.8\%) y sextorsión (12.3\%). Las diferencias fueron significativas entre la población de varones en la mayoría de los riesgos tic que se analizaron. Se concluye que los adolescentes de esta región peruana están expuestos a estos riesgos y, por tanto, se debe orientar el uso responsable de las TIC.

Palabras clave: TIC, adolescentes, acceso a contenidos inapropiados, acoso cibernético.

\section{Abstract}

Information and communication technology (ICT) has had an impact on adolescents across all sectors of society, and using ICT without guidance carries risks. This study evaluates the frequency of risks in ICT use among adolescents in the Junín region (Peru). The sample comprised 955 adolescents aged between 13 and 19 years $(M=15.21, S D=1.07)$ from various provinces in the region. Participants were selected using stratified random sampling. Information was collected with an ad hoc instrument. The results show a significant difference $(<.000)$ in knowledge of risks, which is greater in women. The main risks they are exposed to are access to inappropriate content (46.2\%), sexting (24.9\%), cyberbullying (20.9\%), grooming (20.8\%), sex casting (14.8\%), and sextortion (12.3\%). The differences were significant among males in most of the ICT risks discussed. It is concluded that adolescents in this region of Peru are exposed to these risks and, therefore, should receive guidance on responsible Ict use. 


\section{Introducción}

El avance tecnológico permite el desarrollo acelerado en diferentes actividades, que va desde el trabajo hasta el ocio. Los dispositivos tecnológicos son parte importante del quehacer humano, principalmente de los adolescentes, quienes conviven con múltiples y versátiles aparatos tecnológicos, a los que Prensky (2010) denomina nativos digitales. En este avance, las Tecnologías de Información y Comunicación (TIC) han impactado en los adolescentes de todos los sectores sociales, pues las han hecho parte de su vida (acceso a información multiformato, comunicación, interactividad, etc.); sin embargo, el uso desmedido, sin supervisión ni orientación por parte de los padres y profesores puede conducir a riesgos (Ayuso, 2014; Giménez et al., 2017; Miranda, 2017). De ahí que se considere que las TIC se hayan convertido en un instrumento para agredir con elementos que pueden traspasar espacio y tiempo (Cerezo-Ramírez, 2012).

En la interacción de los adolescentes con las TIC, los riesgos que fueron considerados en esta investigación, con base en las propuestas de Alianza por la Seguridad en Internet (ASI, 2010), ASI (2011), Asociación Chicos.net (2011), Instituto Nacional de Tecnologías de Comunicación (INTECO, 2009) y Pantallas Amigas (2015), fueron:

Acceso a contenidos inapropiados. Visita a cualquier página web con contenido sexual o pornográfico.

Sexting. Envío, reenvío o intercambio de mensajes de texto con contenido sexual o fotografías donde se muestran semidesnudos o desnudos a través del teléfono móvil.

Sexcasting. Emisión de video con contenido sexual a través de webcam, puede ser grabación y compartido por alguna red social. Pueden ser propios o de personas de su entorno.

Sextorsión. Chantaje que hace la persona que tiene en su poder contenidos sexuales en imágenes o videos que obtuvo a través de sexting o sexcasting.

Grooming. Acoso sexual por medio de Internet, en el cual una persona adulta utiliza las redes sociales u otro canal para contactarse con menores de edad y ganar su confianza para luego obtener imágenes o videos con contenido sexual y chantajear amenazando con que difundirá el material obtenido.

Cyberbullying. Acoso haciendo uso de las TIC, se da por parte de un adolescente o grupo de adolescentes en contra de otro de manera reiterativa, con insultos, amenazas, difamación, etc.

En el contexto mundial, en España se aprecia una alta exposición involuntaria a contenidos inapropiados (Catalina et al., 2014) y poca exposición voluntaria, siendo mayor entre varones (Sánchez et al., 2015). También se observa que los adolescentes españoles están expuestos a diferentes riesgos, entre cyberbullying, grooming y sexting (Alfaro et al., 2015). En cuanto al sexting, en España se observa que conocen el significado, sus riesgos y la existencia de casos cercanos, pero no admiten su participación (Fajardo et al., 2013); mientras el estudio de Sánchez et al. (2015) señala que la incidencia de esta práctica es del $7 \%$ o al menos en una ocasión han sexteado (Alonso et al., 2015). Situación similar se observa en Eslovaquia, donde el $9.31 \%$ realizó sexting siendo mayor la implicación en mujeres (Kopecký, 2015). Respecto al sexcasting, en España se evidencia que el 7.3\% de varones y el 10.1\% de mujeres han recibido peticiones para hacer obscenidades frente a la webcam (Catalina et al., 2014). Del Grooming, en Italia un estudio evidenció que el $27 \%$ alguna vez recibió invitaciones para reunirse con personas que conoció en línea, siendo mayor la incidencia en mujeres, de las que el $8.67 \%$ aceptó el encuentro cara a cara (Michele et al., 2017). El riesgo de cyberbullying, en España ronda el 10\%, y diversos estudios sugieren que se tomen medidas para reducirlo (Arnaiz et al., 2016; Garaigordobil, 2015; Giménez et al., 2015; León del Barco et al., 2012; Río et al., 2010; Sabater y López, 2015).

En Estados Unidos los resultados fueron: 6.6\% reportó ser víctima, 5\% agresor y 4.3\% agresor-víctima (Rice et al. 2015); en Italia se registró $12.1 \%$ de ciberacosadores y 7.4\% de cibervíctimas (Baldrya et al., 2016); en Polonia se evidencian más víctimas que perpetradores, y fue en aumento desde el 2010 al 2015 (Tomczyk, 2017). Frente a los riesgos mencionados, se confirma que se requiere una labor preventiva e intervención 
directa por parte de las familias y los centros educativos (Giménez y Maquilón, 2014).

En el contexto latinoamericano, en Colombia se identificó que la frecuencia de riesgos es: sexting (40.3\%); acceso a contenidos inapropiados (24.4\%), siendo menor en mujeres; cyberbullying (15.8\%) y grooming (5.4\%) (Posada, 2015); otro estudio encontró 18.7\% de cyberbullying, dentro de éste $10.7 \%$ fue cibervíctima, 2.5\% ciberagresor y 5.5\% ciberagresor-victimizado (Herrera-López et al., 2017). En Chile se identificó que los varones son los más expuestos en el acceso a contenidos inapropiados, cyberbullying y sexting, mientras que las mujeres lo son en grooming (Mellado y Rivas, 2015). En Ecuador se registró bajo nivel de incidencia de sexting y algunas conductas asociados a grooming (Cajamarca, 2016). En México, más del 50\% estuvo expuesto al sexting (Alemán, 2015), mientras que estudios en Brasil observaron frecuencias de sexting superiores a las de México (Mathias et al., 2017). De ahí que el $40 \%$ de los internautas en Brasil y América Latina ha practicado sexting (Pantallas Amigas, 2015). Con relación al riesgo de cyberbullying otro estudio identificó el 15.7\% de adolescentes expuestos (Maia et al., 2015). En el Perú no se encontraron estudios sobre los riesgos estudiados, sólo de cyberbullying, realizado en la capital donde se identificó un $27.7 \%$ de adolescentes inmersos (con más proporción en varones) (Oliveros et al., 2012), y otro realizado a nivel nacional, donde el resultado fue que al menos $12.1 \%$ sufre este riesgo (Lerner, 2013). En otro estudio, Morales (2015) clasificó a los adolescentes como usuarios sin problemática y con un nivel bajo en el uso de las TIC.

El uso inadecuado de las TIC conlleva riesgos de diferente índole, en el caso de acceso a contenidos inapropiados puede generar problemas físicos, mentales, psicológicos y sociales (Velasco y Gil, 2017), así como afectar la socialización y la percepción de las relaciones sexuales (Sánchez et al., 2015). Las consecuencias del sexting son el chantaje (Sánchez et al., 2015), comportamiento sexual de riesgo, pérdida de reputación social y prestigio al ser insultado, e implicación en cyberbullying (Kopecký, 2015). Del grooming, conlleva a ser engañado y abusado sexualmente, y como consecuencia inclinación a la depresión, baja autoestima, desconfianza, cambios de humor repentinos y bruscos, bajo rendimiento académico, aislamiento, alteraciones del sueño y de la alimentación, ideas e intentos de suicidio (Arab y Díaz, 2015). El cyberbullying implica conductas antisociales (Garaigordobil, 2017) y mayor angustia, tristeza, indefensión, frustración, ira, estrés, somatización, aislamiento, consumo de sustancias, adicción a Internet, ausentismo escolar, bajo rendimiento académico, baja autoestima, problemas para dormir, depresión, ideas o intentos de suicidio y suicidio (D’Auria, 2014; Gámez, 2014; Sánchez et al., 2015); es necesario considerar que las consecuencias permanecen por un período más largo en las víctimas (Tomczyk, 2017). Como consecuencia del cyberbullying y sexting, las mujeres son más vulnerables al suicidio (Navarro, 2017).

En la literatura se encontró que la mayoría de los estudios hace referencia a riesgos de acceso a contenidos inapropiados, sexting, grooming y cyberbullying, pero no abordan sexcasting y sextorsión, además del tipo de exposición a los riesgos. Sólo estudios en España, Colombia y Chile han hecho referencia a cuatro de los seis riesgos que se abordan en este estudio, gran parte analizados de manera independiente. En el contexto peruano el uso de las TIC está en crecimiento y no existen estudios de los riesgos derivados de su mal uso, ello motivó a realizar el análisis conjunto de los distintos riesgos e incidir en aquellos que han sido poco estudiados, los objetivos fueron: a) evaluar la frecuencia de los riesgos en el uso de las TIC en adolescentes de la región Junín; y b) evaluar la frecuencia, conocimiento y tipo de exposición de los riesgos al usar las TIC, según sexo.

\section{Método}

El estudio fue descriptivo transversal. La muestra estuvo conformada por 955 adolescentes del nivel secundario, con edades entre los 13 y los 19 años $(M=15.21$, DT $=1.07)$ residentes en diferentes provincias de la región Junín (Perú): 482 (50.47\%) varones y 473 (49.53\%) mujeres. La selección de participantes se realizó a través de muestreo aleatorio estratificado utilizando como unidad de análisis la Institución Educativa más representativa de cada provincia. La muestra fue representativa con un nivel de confianza del 95\%, el tamaño de la muestra señala que debía aplicarse el instrumento a 383 adolescentes como mínimo. 
El instrumento para recoger los datos (Cuestionario de riesgos en el uso de las TIC) fue construido ad hoc previa revisión bibliográfica (Alianza por la Seguridad en Internet [ASI], 2010, 2011; Asociación Chicos.net, 2011; Instituto Nacional de Tecnologías de Comunicación [INTECO], 2009; Pantallas Amigas, 2015). Para determinar la validez se utilizó el juicio de expertos (dos psicólogos y tres expertos en metodología de investigación), se obtuvo una fiabilidad de $a=.89$ para el conjunto de la muestra. El cuestionario tiene preguntas relacionadas a las características sociodemográficas (lugar de residencia, edad y sexo) y a riesgos en el uso de las TIC.

Para el riesgo Acceso a contenidos inapropiados se plantearon preguntas con respuestas dicotómicas (sí/no). Fueron evaluados con base en las siguientes características: conocimiento (iconoces los riesgos por visitar páginas web con contenido sexual o pornográfico?), exposición voluntaria (¿visitaste páginas web con contenido sexual o pornográfico?), exposición por otros (¿recibiste mensajes por email, Facebook u otra red social con contenido sexual o pornográfico?) e incitación (¿te pidieron que visites páginas web con contenido sexual o pornográfico?).

Para el riesgo Sexting también se plantearon preguntas con respuestas dicotómicas (sí/no) y se evaluó bajo el criterio anterior: conocimiento (¿conoces los riesgos al enviar mensajes por celular con contenido sexual o fotografías de desnudos o semidesnudos?), exposición voluntaria (¿enviaste mensajes por celular con contenido sexual o fotografías donde te muestras desnudo o semidesnudo?), exposición por otros (irecibiste mensajes por celular con contenido sexual o fotografías donde alguien se muestra desnudo o semidesnudo?) e incitación (¿te pidieron que envíes mensajes por celular con contenido sexual o fotografías donde te muestras desnudo o semidesnudo?).

Рara Sexcasting también se plantearon preguntas con respuestas dicotómicas (sí/no) siguiendo la lógica anterior: conocimiento (¿conoces los riesgos por mostrarte desnudo o semidesnudo por webcam o cámara web?), exposición voluntaria (¿utilizaste webcam o cámara web para mostrarte desnudo o semidesnudo?), exposición por otros (¿se mostraron ante ti desnudos o semidesnudos por webcam o cámara web?) e incitación (¿te pidieron mostrarte desnudo o semidesnudo por webcam o cámara web?).

Рara Sextorsión se formularon las preguntas con el mismo criterio: conocimiento (¿conoces los riesgos cuando se amenaza con difundir por Internet, fotos y videos de otras personas donde se muestran desnudos o semidesnudos?), víctima (ite amenazaron con compartir por Internet fotografías o videos donde sales desnudo o semidesnudo si no hacías lo que te pedían?), autor (¿amenazaste con compartir por Internet fotografías o video donde se mostraban desnudos o semidesnudos si no hacían lo que pedías?) e incitación (¿te dijeron que puedes chantajear con compartir por Internet fotografías o video de otras personas donde se muestran desnudos o semidesnudos?).

Del riesgo Grooming se formularon preguntas con respuestas dicotómicas (sí/no) bajo el mismo criterio: conocimiento (¿conoces los riesgos cuando conversas por redes sociales con contactos desconocidos?), conversación con insinuaciones sexuales (¿contactos desconocidos te escribieron por redes sociales con insinuaciones sexuales?), petición de fotos o videos a cambio de algo (¿contactos desconocidos te pidieron a través de redes sociales que envíes fotografías o videos donde te muestras desnudo o semidesnudo a cambio de algo?) y amenaza con robar cuenta (¿te amenazaron con robar tus cuentas de redes sociales si avisabas a tus padres sobre mensajes que intercambiaste con contactos desconocidos?).

Del riesgo Cyberbullying también se formularon preguntas con respuestas dicotómicas (sí/no) con el mismo criterio: conocimiento (¿conoces los riesgos cuando se amenaza, insulta, acosa o se hace otra forma de bullying haciendo uso del celular o Internet?), víctima (¿recibiste por celular o Internet mensajes de texto, imágenes o videos con amenazas, insultos, acoso u otra forma de bullying?), autor (¿enviaste por tu celular o Internet mensajes de texto, imágenes o videos con amenazas, insultos, acoso u otra forma de bullying?) e incitación (¿te dijeron que puedes enviar por celular o Internet mensajes de texto, imágenes o videos con amenazas, insultos, acoso u otra forma de bullying?).

Los participantes fueron seleccionados previo permiso de los directores de las Instituciones Educativas Públicas que aceptaron participar a través de un documento formal; una vez que se concretó el permiso se explicó al docente encargado y a los estudiantes el objetivo del estudio y el procedimiento, sólo se aplicó 
el instrumento a quienes participaron de forma voluntaria.

En cuanto al análisis de datos, las variables cualitativas se presentan según su distribución de frecuencias y porcentajes. Para el contraste de los grupos (según sexo) se utilizó el estadístico U de Mann-Whitney después de comprobar la distribución no normal y la no igualdad de varianzas, las diferencias son consideradas significativas a partir de $p<.05$.

\section{Resultados}

\subsection{Frecuencia de los riesgos al usar las TIC en adolescentes según sexo}

En relación con la frecuencia de riesgos en el uso de las TIC, se encontró que el 65.4\% dice conocer todos los riesgos (tabla I). Además, el acceso a contenidos inapropiados fue el riesgo que se presentó con mayor frecuencia (46.2\%), mientras que sextorsión (12.3\%) la menor frecuencia. Cuando se comparó la variable conocimiento del riesgo con el sexo de los participantes el 71\% de mujeres afirmó tener conocimiento de los riesgos en comparación con el $59.9 \%$ de los varones $(p<.00)$. Además, en los varones los riesgos se manifestaron con mayor frecuencia -a excepción del grooming, que fue más frecuente entre mujeres $(p=$ $.008)$.

Tabla I. Frecuencia de riesgos al usar las tıc y conocimiento del riesgo según género

\begin{tabular}{|c|c|c|c|c|c|c|c|}
\hline \multirow{2}{*}{ Riesgo } & \multicolumn{2}{|c|}{ Masculino } & \multicolumn{2}{|c|}{ Femenino } & \multicolumn{2}{|c|}{ Total } & \multirow[b]{2}{*}{$P$} \\
\hline & $f$ & $\%$ & $f$ & $\%$ & $f$ & $\%$ & \\
\hline Conocimiento del riesgo & 289 & 59.9 & 336 & 71.0 & 625 & 65.4 & $<.000$ \\
\hline Acceso a contenidos inapropiados & 260 & 53.9 & 181 & 38.3 & 441 & 46.2 & $<.000$ \\
\hline Sexting & 136 & 28.2 & 102 & 21.6 & 238 & 24.9 & .012 \\
\hline Sexcasting & 79 & 16.4 & 62 & 13.1 & 141 & 14.8 & .116 \\
\hline Sextorsión & 77 & 16.0 & 40 & 8.5 & 117 & 12.3 & $<.000$ \\
\hline Grooming & 83 & 17.2 & 116 & 24.5 & 199 & 20.8 & .008 \\
\hline Ciberbullying & 116 & 24.1 & 84 & 17.8 & 200 & 20.9 & .009 \\
\hline
\end{tabular}

\subsection{Tipo de exposición al riesgo de los adolescentes de la región Junín}

Del riesgo Acceso a contenidos inapropiados (tabla II), 53.9\% de los varones y $38.3 \%$ de las mujeres señalaron tener conocimiento del riesgo, no habiendo diferencia significativa $(U=110849.50, Z=-1.011, p$ $=.312)$. Siendo la "exposición voluntaria" (53.9\%) más frecuente en varones $(U=65627.00, Z=-13.878, p<$ $.00)$, al contrario del grupo de mujeres $(27.5 \%)$, donde la "exposición por otros" fue más frecuente $(U=$ 102698.50, Z = -3.077, $p=.002$ ). Por otro lado, el tipo de exposición con menor frecuencia fue "exposición voluntaria" en el caso de mujeres (10.8\%) y "exposición por otros" en varones (0\%).

Del Sexting (tabla II), 28.2\% de varones y 21.6\% de mujeres tenían conocimiento del riesgo $(\mathrm{U}=100923.50$, $Z=-3.968, p<.00)$. En cuanto al tipo de exposición, se presentó mayor frecuencia en ambos sexos (17.2\% en varones y $21.2 \%$ en mujeres) la "incitación" ( $U=109453.50, Z=-1.542, p=.123)$. Por otro lado, el tipo de exposición con menor frecuencia fue "exposición voluntaria", siendo del $8.7 \%$ en varones y $4 \%$ en mujeres, habiendo diferencia significativa $(U=108206.00, Z=-3.112, p=.002)$.

Del Sexcasting (tabla II), $16.4 \%$ de varones y $13.1 \%$ de mujeres tenían conocimiento de este riesgo $(U=$ $104427.00, Z=-2.859, p=.004)$. En cuanto al tipo de exposición, el de mayor frecuencia fue la "incitación", siendo en varones el $10.8 \%$ y en mujeres el $13.1 \%(U=112639.00, Z=-2.859, p=.580)$. Por otro lado, el tipo de exposición de menor frecuencia fue "exposición voluntaria", siendo el $3.7 \%$ en varones y $1.3 \%$ en mujeres, con diferencia en ambos grupos ( $U=110951.50, \mathrm{Z}=-2.485, p=.013$ ).

Del riesgo Sextorsión (tabla II), $16 \%$ de los varones y $8.5 \%$ de las mujeres tenían conocimiento de éste. Siendo la "incitación" el tipo de exposición más frecuente en ambos sexos:16\% en varones y 8.5\% en mujeres $(U=105045.50, Z=-3.616, p<.00)$. Por otro lado, el tipo de exposición de menor frecuencia en varones fue ser "víctima" (5.6\%), no habiendo diferencia significativa con mujeres $(U=111772.00, Z=$ - 
$1.302, p=.193$,$) y en el caso de las mujeres fue ser "autor" (2.7\%).$

Del Grooming (tabla II), los adolescentes tenían conocimiento del riesgo evaluado, habiendo diferencias por sexo $(U=94245.50, Z=-6.095, p<.00)$. En cuanto al tipo de exposición, tener "conversaciones con insinuaciones sexuales" fue de mayor frecuencia en ambos sexos, $17.2 \%$ en varones y $24.5 \%$ en mujeres ( $U$ $=105771.50, Z=-2,690, p=.007)$. Por otro lado, el tipo de exposición de menor frecuencia fue el de "recibir amenazas con robar cuenta", siendo del $8.1 \%$ en varones y 6.6\% en mujeres $(U=112017.50, Z=-0.982, p=$ .326).

Con relación al riesgo Cyberbullying (tabla II), existe diferencias en cuanto al conocimiento del riesgo evaluado $(U=99041.50, Z=-4.283, p<.00)$. El tipo de exposición de mayor frecuencia fue el de ser "víctima"en ambos sexos, $24.1 \%$ en varones y $17.8 \%$ en mujeres $(U=103006.00, Z=-3.471, p=.001)$, y ser "autor" fue el tipo de exposición menos frecuente, $11 \%$ en varones y $4.4 \%$ en mujeres, encontrando diferencias significativas $(U=106791.50, Z=-3.461, p=.001)$. 
Tabla II. Tipo de exposición al riesgo de los adolescentes de la región Junín

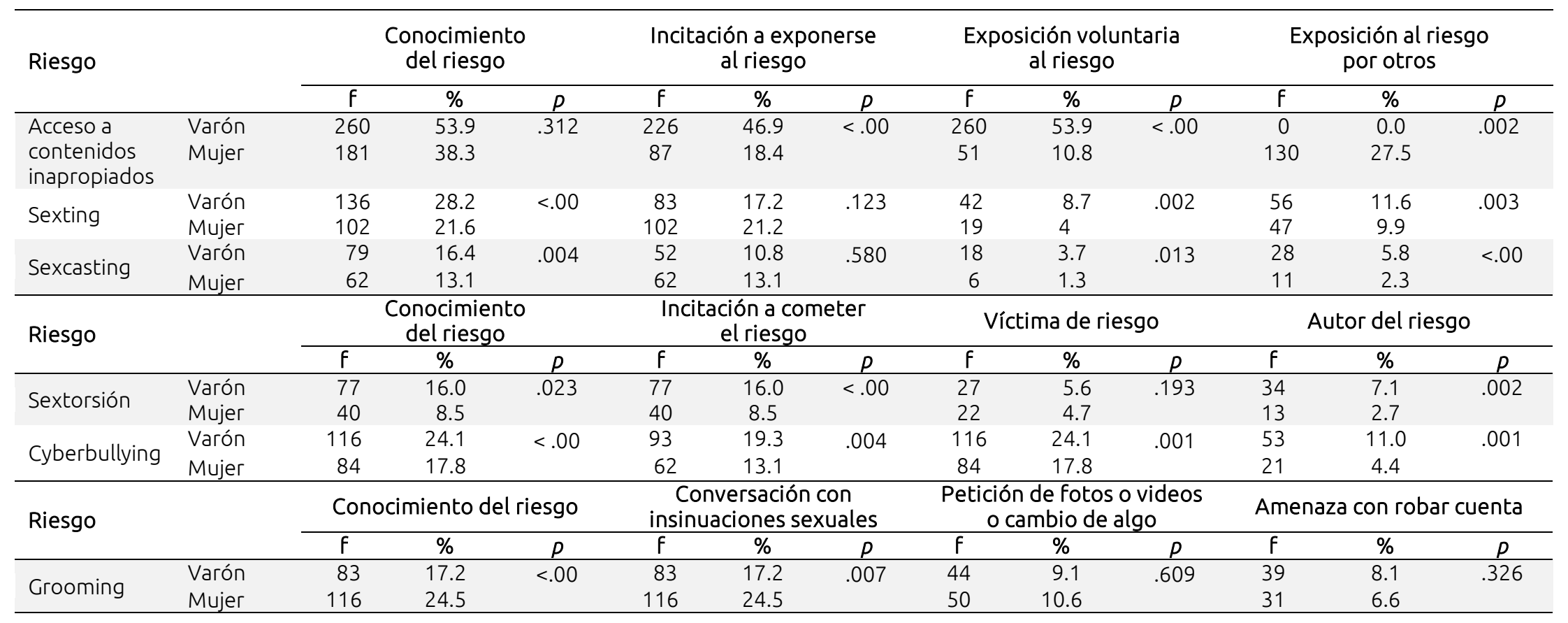




\section{Discusión y conclusiones}

La generación actual de adolescentes y jóvenes ha desarrollado ciertas competencias digitales, adquiridas en su mayoría, de forma autodidacta y posiblemente sin orientación. Esta forma de relacionarse con la tecnología, así como su uso desmedido, expone directa o indirectamente al adolescente y su entorno a diversos riesgos. Cuando analizamos esta problemática en el contexto peruano, verificamos que el uso de Internet se va incrementando cada año, un $68.7 \%$ de los adolescentes accede a Internet (Instituto Nacional de Estadística e Informática [INEI], 2017). Sin embargo, no existen muchos estudios al respecto.

En cuanto al "conocimiento" se observa que 65.4\% de los adolescentes declara conocer los riesgos estudiados. Llama la atención que aun sabiendo la existencia de éstos continúan exponiéndose; podría ser la preponderancia de ciertas características psicológicas de la edad, como la curiosidad, la autosuficiencia, la rebeldía, la búsqueda del desafío, etc. Por otro lado, se aprecia que las mujeres (71\%) conocen más sobre los riesgos en comparación con los varones (59.9\%). Creemos que esto se debe a que en casa, en la escuela y en la sociedad se suele brindar más información a las mujeres sobre diversos riesgos, con vistas a garantizar su protección y prevenir ataques a su integridad física y psicológica. También se encontró que los riesgos más frecuentes en los adolescentes son el acceso a contenidos inapropiados (46.2\%) y el sexting (24.9\%). Por otro lado, el riesgo que se presentó con menor frecuencia fue sextorsión (12.3\%). Nuestro estudio coincide con lo realizado en España (Alfaro et al., 2015), y se contrapone a otros realizados en Colombia, donde el sexting se presentó como más frecuente, seguido de acceso a contenidos inapropiados (Posada, 2015).

En Perú no existen estudios que hablen sobre esta problemática, siendo el de mayor referencia uno realizado en Lima que reporta usuarios sin problemática (Morales, 2015). Consideramos que este riesgo (acceso a contenidos inapropiados) es más frecuente porque en esta etapa se presenta gran interés en conocer la sexualidad, siendo de fácil acceso por esta vía ya que, al parecer, los adolescentes perciben a Internet como fuente de información sexual y en ocasiones la asumen sin tomar una postura responsable y crítica (Doornwaard et al., 2017); además de la inexistencia de control parental otra explicación es la inexistencia de filtros, la carencia de políticas de seguridad informática y la deficiente orientación sobre el uso de páginas web, entre otros.

Cuando se analizaron los riesgos al usar las tic de acuerdo con el sexo, se observó que en casi todos los riesgos estudiados los varones se exponen con mayor frecuencia. Estos resultados coinciden con los resultados obtenidos en España, Colombia y Chile (Alfaro et al., 2015; Catalina et al., 2014; Mellado y Rivas, 2015; Posada, 2015). Consideramos que esto sucede porque los varones tienen mayor libertad en cuanto a su sexualidad; además, de acuerdo con la idiosincrasia del contexto, los padres ejercen mayor control sobre las hijas (Giménez et al., 2017). También educacional y culturalmente a los varones se les da mayor libertad para explorar su sexualidad; a esto se suman las características psicológicas de autosuficiencia, valentía y desafío.

En cuanto al riesgo de acceso a contenidos inapropiados, el tipo de exposición que se presentó con mayor frecuencia fue "exposición voluntaria", siendo significativo en varones, resultados que coinciden con estudios de España, Colombia y Chile (Alfaro et al., 2015; Mellado y Rivas, 2015; Posada, 2015), pero no concuerda con lo obtenido por Catalina et al. (2014). La "exposición por otros" fue el más frecuente en mujeres, por otro lado, y en el caso peruano no se encontraron estudios. Consideramos que la "exposición voluntaria" en el caso de los varones sucede porque se encuentran en etapa de comprensión y desarrollo psicosexual (Corona y Funes, 2015) al igual que las mujeres, y los temas sexuales al no ser abordados de manera científica y responsable dentro de la familia, instituciones educativas y medios de comunicación, cobran importancia dentro de Internet por la facilidad de acceso. También consideramos que esta característica es propia de su desarrollo social y más aún en los círculos de amigos, donde puede convertirse en un desafío visitar páginas con esta información para buscar la inclusión dentro del grupo.

Respecto al sexting, según el tipo de exposición, observamos que "incitación" fue el que se presentó con mayor frecuencia en ambos sexos, no encontrando estudios con resultados iguales, pero sí algunos donde 
se evidencia "exposición por otros", como es el caso de Alfaro et al. (2015), Catalina et al. (2014), Fajardo et al. (2013) y Sánchez et al. (2015). Por otra parte, el tipo de exposición al riesgo que se presentó con menor frecuencia en ambos sexos fue "exposición voluntaria", resultados que coinciden con Alemán (2015), Cajamarca (2016) y Mellado y Rivas (2015), pero discrepa con Alonso et al. (2017) y Kopecký (2015), donde se evidencia mayor frecuencia en mujeres. Observamos que no es frecuente que los adolescentes se expongan de manera voluntaria, habiendo diferencias entre ambos sexos, siendo las mujeres quienes se exponen menos. Esto puede deberse a los consejos recibidos en casa, ya que en esta parte del Perú las familias son bastantes conservadoras, principalmente en las provincias de la sierra (siete de las nueve que conforman la región Junín). Por otro lado, independientemente del sexo, "incitación" fue el tipo de exposición más frecuente en esta población, siendo todavía más frecuente en mujeres. Esto puede ser en gran medida por la masificación y publicación de fotos provocativas para llamar la atención (Fajardo et al., 2013) o por poseer un alta autoestima corporal estética y erótica (Peris et al., 2013) dada la aparente libertad que ofrece internet, que al final puede exponer la intimidad del adolescente de manera peligrosa.

En cuanto al riesgo de sexcasting, el tipo de exposición de mayor frecuencia en ambos sexos (10.8\% y 13.1\%) fue "incitación", resultando concordante con el estudio de Catalina et al. (2014). Por otro lado, el tipo de exposición de menor frecuencia en ambos sexos fue "exposición voluntaria", siendo menor en mujeres; no se encontraron otros estudios que analicen este riesgo como consecuencia, creemos, del entorno cultural, ya que es una sociedad conservadora y saben que al hacerlo se exponen al chantaje sexual. Por otro lado, al estar en pleno desarrollo psicosexual, las mujeres están más expuestas a que les inciten a hacer grabaciones íntimas. Encontramos una clara diferenciación entre varones y mujeres respecto a la exposición voluntaria, lo que evidencia que las mujeres son más cautelosas al momento de utilizar una cámara web.

En cuanto al riesgo de sextorsión, éste se presenta con menos frecuencia (12.3\%); el tipo de exposición más frecuente en ambos sexos fue "incitación", mientras que el de menor frecuencia fue ser "víctima" en varones y ser "autor" en mujeres. No se encontraron estudios que analicen este riesgo. Si bien es cierto que es el riesgo menos frecuente, se puede deducir desconocimiento de las consecuencias de este riesgo.

Del grooming, respecto al tipo de exposición "tener conversación con insinuaciones sexuales" tuvo mayor frecuencia en ambos sexos, siendo mayor en mujeres; mientras que el de menor frecuencia fue "amenaza con robar cuenta", no se encontraron estudios que consideren estos tipos de exposición, pero sí algunos similares en España, donde hacen alusión a conductas de riesgo (Fernández-Montalvo et al., 2015), contacto con desconocidos (Alfaro et al., 2015; Catalina et al., 2014) siendo mayor el porcentaje en mujeres (Michele et al., 2017), y en Chile se encontró que una pequeña minoría se ha expuesto a este riesgo, siendo las mujeres más propensas (Mellado y Rivas, 2015). Consideramos que los adolescentes interactúan con desconocidos conversando con insinuaciones sexuales por características de la edad, principalmente porque esta etapa es de comprensión y desarrollo psicosexual (Corona y Funes, 2015), y muchas de las preguntas lo canalizan mejor con un amigo virtual; por tanto, se infiere que ni la familia ni la escuela están asumiendo su rol.

Respecto al cyberbullying, el tipo de exposición más frecuente en ambos sexos fue ser "víctima", en mayor proporción varones (24.1\%) que mujeres (17.8\%), resultados que coinciden con el estudio de Lerner (2013) y Tomczyk (2017), pero no con los obtenidos en España por Arnaiz et al. (2016), Giménez (2015) y Sabater y López $(2015$,$) quienes encontraron mayor presencia de mujeres en el papel de víctimas. En nuestro$ estudio, al igual que Herrera-López et al. (2017), se encontró que el tipo de exposición menos frecuente fue "autor", resultado que no coincide con lo encontrado por Alfaro et al. (2015), Baldrya et al. (2016) y Mellado y Rivas (2015). Tampoco concuerda con estudios en España (León del Barco et al. 2012; Río et al., 2010) y en Norteamérica (Rice et al., 2015) donde encontraron que no hay diferencia según el tipo de exposición al riesgo y que apenas supera el 10\%, a excepción de un estudio hecho en Brasil (Maia et al., 2015), en el que se observa que más del $15 \%$ ha estado expuesto a este riesgo, al igual que un estudio realizado en Perú, siendo más frecuente en varones (Oliveros et al., 2012).

Si bien el sistema educativo peruano ha implementado el programa de prevención del bullying, se ha abordado el tema de violencia física, psicológica, verbal y sexual, pero los adolescentes ven en las redes sociales un escenario que no abarca la escuela y las cifras de cyberbullying van en aumento. Por otro lado, 
los varones en un porcentaje mayor fue víctima que las mujeres, esto posiblemente se debe a que ellas no callan, buscan protección y lo expresan a sus padres, profesores o amistades, mientras que los varones tratan de solucionar sus dificultades por el prejuicio de que un varón no se debe quejar, no debe llorar, etc.

Es necesario reevaluar la enseñanza y el control del uso responsable de tıc: de los padres de familia, quienes deben autoeducarse para supervisar a sus hijos, además de convertirse en un buen ejemplo de uso (Arab y Diaz, 2015), buscar las aplicaciones comunes que usan sus hijos y pedir que les muestren el funcionamiento (D’Auria, 2014); de los profesores, que deben presentar ejemplos concretos de daños causados a la víctima (Kopecký, 2015); de las Instituciones Educativas; del gobierno -como el caso de Corea del Sur, que inició un movimiento para bloquear intercambio de contenido obsceno compartido entre jóvenes menores de 18 años (Song et al., 2018); y de la sociedad en general. Esto ayudaría a que los adolescentes desarrollen competencias digitales y al mismo tiempo aprendan a identificar los riesgos. Esta idea llevaría a que los adolescentes aprendan a convivir con las TIC, es decir, aprender a gestionar la ciberconvivencia, haciendo uso consciente y responsable de las mismas aprovechando al máximo las ventajas que ofrecen las TIC y ejerciendo una ciudadanía digital responsable (Castro, 2013).

Por último, se evidencian algunas limitaciones del estudio: 1) el instrumento, al haber sido construido ad hoc y no ser estandarizado, podría conllevar cierto grado de sesgo en las respuestas; 2) el estudio se realizó sólo en Instituciones Educativas Públicas, por lo que sería conveniente incluir instituciones privadas y dividir en grupos (10-14 años, 15-17 años y 18-20 años) para ver la predominancia de los riesgos con la edad; 3 ) al abordar seis riesgos es posible que se hayan omitido algunas conductas específicas de cada riesgo, por tanto, es necesario profundizar el estudio; 4) debido a que el estudio fue de corte transversal no se pudo determinar relación causal. Estudios futuros podrían abordar: a) riesgos en el uso de las Tic desde las víctimas, agresores y observadores; b) causas y consecuencias de los riesgos al usar las TIC, c) programa de intervención para el manejo responsable de las TIc y d) convivencia digital.

\section{Referencias}

Alemán, R. M. (2015). Sexting y la adolescencia: el mal uso de la tecnología. Revista I.C. investig@cción, 4(7), 47-51. http://revistaic.instcamp.edu.mx/revistas/revista7

Alfaro, M., Vásquez, M. E., Fierro, A., Herrero, B., Muñoz, M. F. y Rodríguez, L. (2015). Uso y riesgos de las Tecnologías de la Información y Comunicación en adolescentes de 13-18 años. Acta Pediátrica Española, 73(6), 126-135.

Alianza por la Seguridad en Internet. (2010). Sexting: cuando la diversión se convierte en delito. El efecto Internet, 2(2), 4-10. https://www.yumpu.com/es/document/view/14677011/sexting-alianza-por-laseguridad-en-internet

Alianza por la Seguridad en Internet. (2011). Guía ASI para prevención del ciber-bullying. ASI-México. http://asimexico.org/joomlaspan/index.php?option=com content\&view=article\&id=72\&ltemid=67

Alonso, P., Rodríguez, Y., Lameiras, M. y Martínez, R. (2017). Las motivaciones hacia el sexting de los y las adolescentes gallegos/as. Revista de Estudios e Investigación en Psicología y Educación, Extr.(13), 047-051. https://doi.org/10.17979/reipe.2017.0.13.2280

Arab, E. y Díaz, A. (2015). Impacto de las redes sociales e internet en la adolescencia: aspectos positivos y negativos. Revista Médica Clínica Las Condes, 26(1), 7-13. https://doi.org/10.1016/i.rmclc.2014.12.001

Ayuso, L. (2014). Padres y jóvenes ante los riesgos de las TIC en España. Metamorfosis, 1, 5-20. https://revistametamorfosis.es/index.php/metamorfosis/article/view/18

Baldrya, A., Farringtonb, D. y Sorrentino, A. (2016). Cyberbullying in youth: a pattern of disruptive 
behaviour. Psicología Educativa, 22(1), 19-26. https://doi.org/10.1016/i.pse.2016.02.001

Cajamarca, M. (2016). Identificación de los niveles de "sexting" en adolescentes [Tesis de pregrado. Universidad de Cuenca]. Repositorio institucional http://dspace.ucuenca.edu.ec/handle/123456789/24563

Castro, A. (2013). Formar para la ciberconvivencia. Internet y prevención del ciberbullying. Revista Integra Educativa, VI(2), 49-70. http://www.scielo.org.bo/pdf/rieiii/v6n2/v6n2a04.pdf

Catalina, B., López de Ayala, M. y García, A. (2014). Los riesgos de los adolescentes en Internet: los menores como actores y víctimas de los peligros de Internet. Revista Latina de Comunicación Social, 69, 462-485. http://doi.org/10.4185/RLCS-2014-1020

Cerezo, F., Arnaiz, P., Gimenez, A. M. y Maquilón, J. (2016). Online addiction behaviors and cyberbullying among adolescents. Anales de Psicología, 32(3), 761-769. http://dx.doi.org/10.6018/analesps.32.3.217461

Cerezo-Ramírez, F. (2012). Bullying a través de las tic. Boletín Cientifico Sapiens Research, 2(2), 24-29. https://www.srg.com.co/bcsr/index.php/bcsr/article/view/61

Corona, F. y Funes, F. (2015). Abordaje de la sexualidad en la adolescencia. Revista Médica Clínica Las Condes, 26(1), 74-80. https://doi.org/10.1016/j.rmclc.2014.12.004

D'Auria, J. (2014). Cyberbullying resources for youth and their families. Journal of Pediatric Health Care, 28(2), e19-e22. https://doi.org/10.1016/i.pedhc.2013.11.003

Del Río, J. d., Sádaba, C. y Bringué, X. (2010). Menores y redes ¿sociales?: de la amistad al cyberbullying. Revista Estudios de Juventud, 88, 115-129. http://www.injuve.es/sites/default/files/RJ88-09.pdf

Doornwaard, S. M., Boer, F., Vanwesenbeeck, I., Nijnatten, C., Bogt, T. y Eijnden, R. (2017). Dutch adolescents' motives, perceptions, and reflections toward sex-related internet use: results of a web-based focus-group study. The Journal of Sex Research, 54(8), 1038-1050.

http://doi.org/10.1080/00224499.2016.1255873

Fajardo, I., Gordillo, M. y Regalado, A. (2013). Sexting: nuevo uso de la tecnología y la sexualidad en adolescentes. International Journal of Develompental and Educational Psychology, 1(1), 521-534.

http://infad.eu/RevistalNFAD/index.php/publicaciones/revista-infad-2013/no1-volumen-1-pp.-521-534/

Fernández-Montalvo, J., Peñalva, A. e Irazabal, I. (2015). Hábitos de uso y conductas de riesgo en Internet en la preadolescencia. Comunicar, XXI/(44), 113-120.

https://www.revistacomunicar.com/index.php?contenido=detalles\&numero=44\&articulo=44-2015-12

Gámez, M. (2014). E-impacto del uso de las tecnologías de la información y la comunicación en la salud mental. Formación Médica Continuada en Atención Primaria, 21(8), 454-463.

https://doi.org/10.1016/S1134-2072(14)70819-9

Garaigordobil, M. (2015). Cyberbullying in adolescents and youth in the Basque Country: changes with age. Anales de psicología, 31(3), 1069-1076. http://dx.doi.org/10.6018/analesps.31.3.179151

Garaigordobil, M. (2017). Conducta antisocial: conexión con bullying/cyberbullying y estrategias de resolución de conflictos. Psychosocial Intervention, 26(1), 47-54. https://doi.org/10.1016/i.psi.2015.12.002

Giménez, A. M., Luengo, J. A. y Bartrina, M. J. (2017). ¿Qué hacen los menores en Internet? Usos de las TIC, estrategias de supervisión parental y exposición a riesgos. Electronic Journal of Research in Educational Psychology, 15(3), 533-552. http://dx.doi.org/10.14204/ejrep.43.16123

Giménez, A., Maquilón, J. y Arnaiz, P. (2015). Usos problemáticos y agresivos de las tIC por parte de 
adolescentes implicados en cyberbullying. Revista de Investigación Educativa, 33(2), 335-351.

http://dx.doi.org/10.6018/rie.33.2.199841

Giménez-Gualdo, A., Maquilón, J. J. y Arnaiz, P. (2014). Acceso a las tecnologías, rendimiento académico y cyberbullying en escolares de secundaria. Revista Iberoamericana de Psicología y Salud, 5(2), 119-133.

Herrera-López, M., Romera, E. y Ortega-Ruiz, R. (2017). Bullying y cyberbullying en Colombia; coocurrencia en adolescentes escolarizados. Revista Latinoamericana de Psicología, 49(3), 163-172.

https://doi.org/10.1016/i.rlp.2016.08.001

Instituto Nacional de Estadística e Informática. (2017). Las Tecnologías de Información y Comunicación en los hogares: abril, mayo, juio 2017. Portal del Estado Peruano.

http://m.inei.gob.pe/media/MenuRecursivo/boletines/03-informe-tecnico-n03 tecnologias-de-

informacion-abr-may-jun2017.pdf

Instituto Nacional de Tecnologías de Comunicación. (2009). Estudio sobre hábitos seguros en el uso de las TIC por niños y adolescentes y e-confianza de sus padres. Observatorio de la seguridad de la información.

Kopecký, K. (2015). Sexting among slovak pubescents and adolescent children. Procedia-Social and Behavioral Sciences, 203, 244-250. https://doi.org/10.1016/i.sbspro.2015.08.289

León del Barco, B., Castaño, E., Fajardo, F. y Gómez, T. (2012). Cyberbullying en una muestra de estudiantes de Educación Secundaria: variables moduladoras y redes sociales. Electronic Journal of Research in Educational Psychology, 10(27), 771-788. http://dx.doi.org/10.25115/ejrep.v10i27.1527

Lerner, R. (2013,17 de septiembre). El 12.1\% de escolares en el Perú sufre de cyberbullying. La República. https://larepublica.pe/archivo/739024-el-121-de-escolares-en-el-peru-sufre-de-ciberbullying/

Maia, C., Lopes, S., Lopes, T., Madureira, C., Oliveira, F., Fontes, C. y Fonseca, P. (2015). Geração Digital: Riscos e Competências [Generación digital: riesgos y competencias]. Acta Pediátrica Portuguesa, 46(3), 232238. https://doi.org/10.25754/pip.2015.6285

Mathias, P., Melo, R. y Rodrigues, G. (2017). Uso de redes sociais e prática do sexting: o que dizem alunos e alunas de uma escola pública [Uso de las redes sociales y práctica del sexting: lo que dicen los estudiantes de una escuela pública]. V Simpósio Internacional em Educação Sexual: saberes/trans/versais currículos identitários e pluridades de gênero. Maringá. http://www.sies.uem.br/trabalhos/2017/3168.pdf

Mellado, E. y Rivas, J. (2015). Riesgos en el uso de tic en alumnos de enseñanza básica: el caso de un colegio en Chillán, Chile. Integra Educativa, VIII(3), 147-166.

Michele, M. F., Toaff, J., Pulvirenti, G., Settanni, C., Colao, E., Lavano, S. M., Cemicetti, R., Cotugno, D., Perrotti, G., Meschesi, V., Montera, R., Zepponi, B., Rapetto, U. y Marotta, R. (2017). Internet use and access, behaviour, cyberbullying, and grooming: results of an investigative whole city survey of adolescents. Interactive Journal of Medical Research, 6(2), 9-14. http://doi.org/10.2196/ijmr.6231

Morales, J. (2015). Uso de las tecnologías de información y comunicación en adolescentes de las instituciones educativas públicas del Distrito Mi Perú. Anales de la Facultad de Medicina, 76(3), 257-259. https://doi.org/10.15381/anales.v76i3.11235

Navarro, N. (2017). El suicidio en jóvenes en España: cifras y posibles causas. Análisis de los últimos datos disponibles. Clínica y Salud, 28(1), 25-31. https://doi.org/10.1016/j.clysa.2016.11.002

Oliveros, M., Amemiya, I., Condorimay, Y., Oliveros, R., Barrientos, A. y Rivas, E. (2012). Cyberbullying - Nueva tecnología electrónica al servicio del acoso escolar en alumnos de dos distritos de Lima, Perú. Anales de la Facultad de Medicina, 73(1), 8-13. http://dx.doi.org/10.15381/anales.v73i1.804 
Ortíz, M. I. y Miranda, C. N. (2017). Control parental y el uso del internet en los adolescentes de la unidad educativa "Pichincha" de la ciudad de Ambato [Tesis de licenciatura. Universidad Técnica de Ambato]. https://repositorio.uta.edu.ec/ispui/handle/123456789/25687

Pantallas Amigas. (2015). Estudio online "Sexting, una amenaza desconocida". Pantallas Amigas. http://www.sexting.es/estudio-sexting/

Peris, M., Maganto, C. y Kortabarria. L. (2013). Autoestima corporal, publicaciones virtuales en las redes sociales y sexualidad en adolescentes. European Journal of Investigation in Health, Psychology and Education, 3(2), 71-180. https://doi.org/10.30552/ejihpe.v3i2.39

Posada, L. (2015). Riesgos en el uso de Internet en los estudiantes de la Institución Educativa Joaquín Cárdenas Gómez del Municipio San Carlos (Antioquía) para el año escolar 2015 [Tesis de maestría. Universidad Pontificia Bolivariana].

Prensky, M. (2010). Nativos e inmigrantes digitales. Distribuidora SEK.

Rice, E., Petering, R., Rhoades, H., Winetrobe, H., Goldbach, J., Plant, A., Montoya, J. y Kordic, T. (2015). Cyberbullying perpetration and victimization among middle-school students. American Journal Public Health, 105(3), 66-77. http://doi.org/10.2105/AJPH.2014.302393

Sabater, C. y López, L. (2015). Factores de riesgos en el cyberbullying. Frecuencia y exposición de los datos personales en Internet. International Journal of Sociology of Education, 4(1), 1-25.

http://dx.doi.org/10.4471/rise.2015.01

Sánchez, L., Crespo, G., Aguilar, R., Bueno, F. J., Benavent, R. y Valderrama, J. C. (2015b). Los adolescentes y las Tecnologías de la Información y la Comunicación (TIC).

http://digital.csic.es/bitstream/10261/132633/1/TICPadres.pdf

Sánchez, V., Muñoz-Fernández, N. y Vega, E. (2015a). El cibercortejo en la adolescencia: riesgos e impacto emocional de la ciberconducta sexual. Psychology, Society \& Education, 7(2), 227-240.

http://dx.doi.org/10.25115/psye.v7i2.535

Song, J., Song, T.M. y Lee, J. R. (2018). Stay alert: forecasting the risks of sexting in Korea using social big data. Computers in Human Behavior, 81, 294-302. https://doi.org/10.1016/i.chb.2017.12.035

Tomczyk, L. (2017). Cyberbullying in 2010 and 2015 - a perspective on the changes in the phenomenon among adolescents in Poland in the context of preventive action. Children and Youth Services Review, 75, 50-60. https://doi.org/10.1016/j.childyouth.2017.02.017

Urbas, A. (2011). Programa uso seguro, responsable y productivo de las TIC. Manual de enfoque teórico. Asociación Chicos.net. https://www.chicos.net/item/manual-de-enfoque-teorico-sobre-uso-responsable-yseguro-de-las-ticl

Velasco, A. y Gil, V. (2017). La adicción a la pornografía: causas y consecuencias. Drugs and Addictive Behavior, 2(1), 122-130. http://dx.doi.org/10.21501/24631779.2265 